\title{
GEOCHEMICAL CORRELATIONS IN ROBERTS VICTOR EGLOGITES.
}

$$
\text { Kirkley, }{ }^{(1)} \text { M.B.; Gurney, }{ }^{(1)}{ }_{J . J . ;} \text { Harte, }{ }^{(2)} \text { B. and Helmstaedt, }{ }^{(3)} H \text {. }
$$

(1) Dept. of Geochemistry, Univ. Cape Town, Rondebosch 7700, South Africa; (2) Grant Inst. of Geology, Univ. Edinburgh, West Mains Road, Edinburgh, EH9 3JW; (3) Dept. of Geological Sciences, Queen's Univ., Kingston, Ontario, Canada, K7L $3 N 6$.

Eclogite xenoliths in kimberlites may have originated (1) as cumulates from melts of garnet peridotite, (2) as fragments of subducted oceanic crust, and/or (3) through combinations of models 1 and 2 , e.g. by the transformation of subcontinental garnet clinopyroxenites by Na-bearing metasomatic fluids derived from a subducted slab.

The strongest geochemical evidence presently available is carbon and oxygen stable isotope data which supports the subduction model. $\delta^{13} \mathrm{C}$ values of diamonds containing eclogitic inclusions $(-34 \%$ to $+2.7 \%$ oo) are compatible with crustal (organic and carbonate) carbon sources. Enriched $\delta^{18} O$ values in Group I eclogites $(>6 \%)$ indicate that they could represent hydrothermally altered basalts, whereas Group II eclogites, with $\delta^{18} 0$ values $<6^{0} / 00$, could represent gabbros altered at higher temperatures and lower water/rock ratios. No mantle (high temperature) processes are presently known which can account for the oxygen isotope characteristics of the eclogites.

If the eclogites were originally crustal rocks, it is to be expected that the identity of their protoliths is difficult to prove by geochemical means, considering the wide range of processes which could affect their compositions, e.g. submarine hydrothermal alteration and weathering, low to high grade metamorphism, and mantle metasomatism. On the other hand, if the eclogites represent mantle cumulates, more coherent geochemical trends would be expected. This study examines correlations among major element, trace element, and oxygen isotope compositions in Roberts Victor eclogites in order to further test the proposed models. 